\title{
Heart Transplantation Ameliorates Ambulation Capacity in Patients With Muscular Dystrophy \\ - An Analysis of 9 Cases -
}

\author{
Osamu Seguchi, MD, PhD; Kensuke Kuroda, MD; Tomoyuki Fujita, MD, PhD; \\ Yuto Kumai, MD; Seiko Nakajima, MD; Takuya Watanabe, MD, PhD; \\ Masanobu Yanase, MD; Yorihiko Matsumoto, MD; Satsuki Fukushima, MD, PhD; \\ Koichi Kimura, MD, PhD; Norihide Fukushima, MD, PhD
}

\begin{abstract}
Background: Heart transplantation ( $\mathrm{HTx}$ ) is reported to have a comparable effect on the prognosis of heart failure patients without muscular disease and for those with muscular dystrophy (MD). However, little is known about the changes in muscular diseases in patients with MD after HTx.
\end{abstract}

Methods and Results: We assessed the ambulatory capacity of 9 patients with MD who underwent HTx. All patients demonstrated improvement in ambulation to varying degrees and 1 patient successfully climbed Mount Fuji 3.8 years after HTx.

Conclusions: HTx potentially improves not only the prognosis but also the ambulatory capacity of patients with MD.

Key Words: Advanced heart failure; Ambulation; Exercise capacity; Heart transplantation; Muscular dystrophy

$\mathbf{P}$ atients with muscular dystrophy (MD) often develop congestive heart failure caused by secondary dilated cardiomyopathy (DCM). Advanced heart failure because of secondary DCM is an important prognostic factor for patients with MD, and left ventricular assist devices (LVAD) and heart transplantation (HTx) are effective therapies when patients are unresponsive to conventional treatment.1,2 Studies have shown that clinical outcomes after LVAD implantation and HTx are comparable among patients with MD and with idiopathic DCM without skeletal muscle diseases. ${ }^{3,4}$ Furthermore, skeletal muscle diseases improve after LVAD, but the effect of HTx on ambulatory capacity in patients with MD is uncertain.

Here, we discuss a series of patients with MD and analyze changes in their ambulatory capacity after HTx.

\section{Methods}

\section{Study Population}

The medical records of all patients who underwent HTx at the National Cerebral and Cardiovascular Center were retrospectively reviewed: 109 patients underwent HTx between 1999 and 2017, and $9(8 \%)$ were diagnosed with MD-related cardiomyopathy. To be listed as HTx candidates, patients with MD must meet institutional and conventional criteria for HTx candidacy including: (1) independent ambulation, and (2) no use of respirator for respiratory muscle weakness.

\section{Exercise Training Protocol}

Exercise training in the early phase after HTx consisted of standing, and walking, which was tailored to each patient's exercise capacity. At 3 weeks after HTx, a supervised exercise program consisting of walking, bicycle ergometer, and low-intensity resistance training was started. If patients had weakened muscular strength, a tailor-made exercise program consisting of standing and walking was applied. Values of serum creatine kinase were closely monitored during rehabilitation.

\section{Results}

Table demonstrates the clinical characteristics of the 9 patients with MD. All patients were supported by LVAD for an average of $1,220 \pm 243$ days. Patients 3, 4, 6, 7, 8, and 9 were diagnosed with Becker MD and patient 5 with $\alpha$-dystroglicanopathy. Patients 1 and 2 were diagnosed with dystrophinopathy based on patchy immunohistochemical dystrophin protein staining patterns in explanted native hearts after HTx. All HTx procedures were performed

Received September 19, 2018; revised manuscript received November 29, 2018; accepted January 8, 2019; J-STAGE Advance Publication released online January 26, 2019 Time for primary review: 42 days

Department of Transplant Medicine (O.S., K. Kuroda, Y.K., S.N., T.W., M.Y., N.F.), Department of Cardiovascular Surgery (T.F., Y.M., S.F.), National Cerebral and Cardiovascular Center, Suita; Department of Advanced Medical Science, The Institute of Medical Science, The University of Tokyo, Tokyo (K. Kimura), Japan

Mailing address: Osamu Seguchi, MD, PhD and Norihide Fukushima, MD, PhD, Department of Transplant Medicine, National Cerebral and Cardiovascular Center, 5-7-1 Fujishiro-dai, Suita 565-8565, Japan. E-mail: oseguchi@ncvc.go.jp; nori@ncvc.go.jp

ISSN-1346-9843 All rights are reserved to the Japanese Circulation Society. For permissions, please e-mail: cj@j-circ.or.jp 


\begin{tabular}{|c|c|c|c|c|c|c|c|c|c|c|c|c|}
\hline \multirow{2}{*}{$\begin{array}{l}\text { Patient } \\
\text { no. }\end{array}$} & \multirow{2}{*}{$\begin{array}{c}\text { Age at } \\
\text { HTx } \\
\text { (years) }\end{array}$} & \multirow[t]{2}{*}{ Sex } & \multirow{2}{*}{$\begin{array}{l}\text { Height } \\
\text { (m) }\end{array}$} & \multirow{2}{*}{$\begin{array}{c}\text { Weight } \\
\text { (kg) }\end{array}$} & \multirow{2}{*}{$\begin{array}{l}\text { BSA } \\
\left(m^{2}\right)\end{array}$} & \multirow{2}{*}{ Diagnosis } & \multirow{2}{*}{$\begin{array}{l}\text { Type of } \\
\text { LVAD }\end{array}$} & \multirow{2}{*}{$\begin{array}{l}\text { LVAD } \\
\text { support } \\
\text { (days) }\end{array}$} & \multirow{2}{*}{$\begin{array}{l}\text { CK at } \\
\text { HTx } \\
\text { (U/L) }\end{array}$} & \multirow{2}{*}{$\begin{array}{c}\text { Mobility } \\
\text { before HTx }\end{array}$} & \multicolumn{2}{|c|}{$\begin{array}{c}\text { Respiratory } \\
\text { function }\end{array}$} \\
\hline & & & & & & & & & & & $\%$ VC & FEV1.0\% \\
\hline 1 & 25 & M & 1.6 & 64 & 1.67 & Dystrophinopathy & NIPRO-LVAD & 1,592 & 428 & Ambulatory & NA & NA \\
\hline 2 & 26 & $M$ & 1.67 & 42.8 & 1.45 & Dystrophinopathy & NIPRO-LVAD & 1,518 & 423 & Ambulatory & NA & NA \\
\hline 3 & 17 & $M$ & 1.71 & 62 & 1.73 & Becker & NIPRO-LVAD & 955 & 1,315 & Ambulatory & 75.6 & 85 \\
\hline 4 & 32 & M & 1.65 & 72 & 1.79 & Becker & EVAHEART & 908 & 2,011 & Ambulatory & 92.3 & 86.6 \\
\hline 5 & 28 & M & 1.71 & 53 & 1.61 & a-dystroglicanopathy & HeartMate II & 1,116 & 1,206 & Ambulatory & 68.4 & 81 \\
\hline 6 & 20 & M & 1.63 & 74.5 & 1.8 & Becker & HeartMate II & 1,221 & 2,273 & Wheelchair & 87.5 & 84.2 \\
\hline 7 & 30 & M & 1.53 & 49 & 1.44 & Becker & NIPRO-LVAD & 1,417 & 1,091 & Wheelchair & 77.8 & 80.2 \\
\hline 8 & 19 & M & 1.69 & 68 & 1.78 & Becker & DuraHeart & 1,058 & 3,662 & Ambulatory & 67.7 & 69.2 \\
\hline 9 & 42 & $M$ & 1.71 & 53 & 1.61 & Becker & NIPRO-LVAD & 1,194 & 89 & Wheelchair & 108.3 & 75.2 \\
\hline
\end{tabular}

Becker, Becker muscular dystrophy; BSA, body surface area; CK, creatine kinase; FEV1.0\%, forced expiratory volume percentage in $1 \mathrm{~s}$; HTx, heart transplantation; LVAD, left ventricular assist device; NA, not available; \%VC, vital capacity percentage.

A

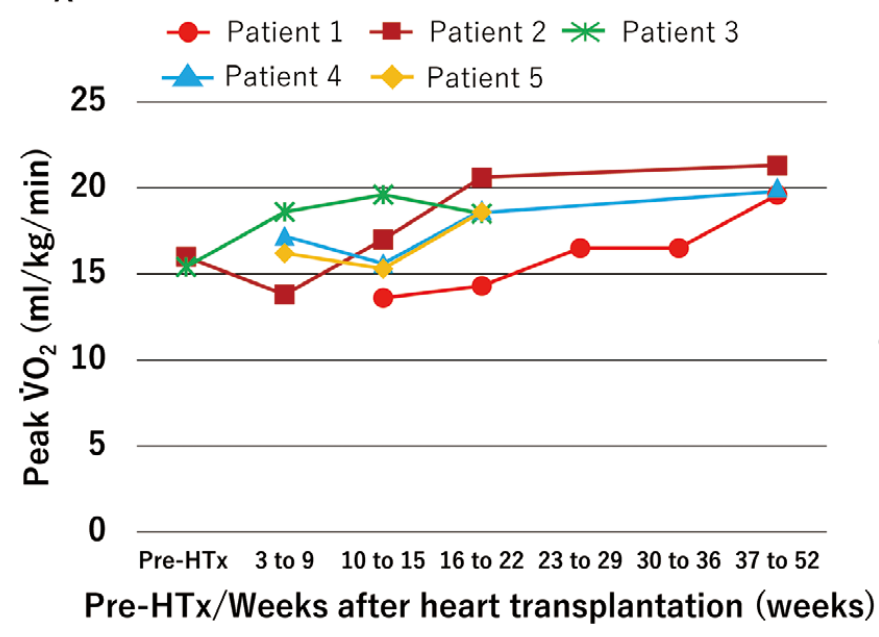

B

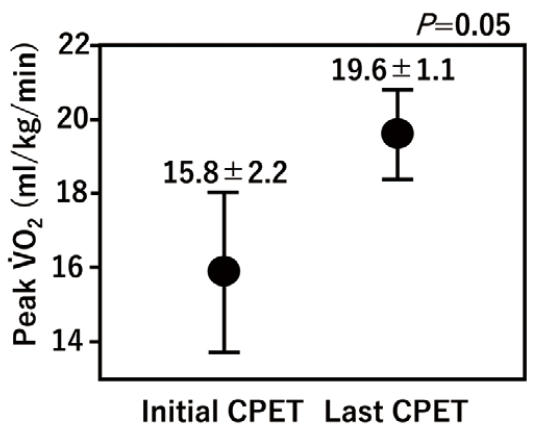

Initial CPET Last CPET

Figure. Changes in maximum oxygen uptake (Peak $\left.\mathrm{V}_{2}\right)$ in 5 patients (patients 1-5) after undergoing heart transplantation $(\mathrm{HTx}$ ) (A). HTx recipients who were able to join the cardiac rehabilitation programs underwent serial cardiopulmonary exercise tests regularly up to 12 months after HTx. Two patients (patients 2 and 3) underwent cardiopulmonary exercise testing before HTx while on left ventricular assist device support. Comparison of the values of maximum oxygen uptake (Peak $\left.\mathrm{VO}_{2}\right)$ between initial cardiopulmonary exercise test (CPET) and the last CPET for each patient (patients 1-5) (B). All patients except for patient 3 demonstrated recovery of ambulatory capacity.

with a modified bicaval method. Immunosuppression was started with tacrolimus, mycophenolate, and corticosteroids. Although all patients were ambulatory to varying degrees when listed as transplant candidates, patients 6, 7, and 9 almost lost the ability to ambulate just before receiving HTx after a long waiting period. The other 6 patients remained ambulatory at the time of HTx. Patients 1-5 underwent serial cardiopulmonary exercise testing (CPET) after HTx. Figure A shows the changes in maximum oxygen uptake $\left(\right.$ Peak $\left.\dot{\mathrm{VO}}_{2}\right)$ in those 5 patients. Peak $\dot{\mathrm{VO}}_{2}$ increased from initial to last CPET after HTx in all patients except patient $3(15.8 \pm 2.2$ vs. $19.6 \pm 1.1 \mathrm{~mL} / \mathrm{kg} / \mathrm{min}, \mathrm{P}=0.05)$ (Figure B). These 5 patients returned to normal daily activities without difficulty. Of the 4 patients who could not undergo CPET, patient 8 was ambulatory but suffered from talipes equinus. Patients 6 and 7 underwent serial 6-min walk tests (6MWT) and patient 6 , who had a positive
Gowers' sign, demonstrated obvious improvement in 6MWT from $290 \mathrm{~m}$ to $375 \mathrm{~m}$ after HTx. Patient 7 also showed improvement in 6MWT from $155 \mathrm{~m}$ to $240 \mathrm{~m}$ (Supplementary Figure 1). We assessed the ambulatory capacity of patients 7,8 and 9 before and after HTx using our unique, previously reported ambulation scale (Supplementary Figure 2; Supplementary Table). ${ }^{3}$ Patient 8 ambulated independently throughout his pre- and post-HTx course. Although patients 7 and 9 demonstrated a decrease on the ambulation scale from 2 before HTx, to 0 and 1 , respectively, immediately after HTx, their ambulation scales improved to 3 with aggressive but steady physical rehabilitation. With respect to survival, Patient 2 died of post-transplant lymphoproliferative disorder 3.5 years after HTx, but the remaining 8 patients enjoyed good health for an average of 4.3 \pm 2.5 years (range, 0.9-7.7 years) of follow-up after HTx. 


\section{Discussion}

We report 9 patients with MD who underwent HTx. Although all patients were ambulatory when listed as transplant candidates, patients 6,7 , and 9 almost became unable to ambulate independently while awaiting HTx on LVAD support. Initially, we thought that their inability to ambulate independently resulted from progression of MD and that they would not recover even after HTx. However, all patients demonstrated improvement in ambulation. Especially patient 9 who underwent HTx at 42 years of age, which almost met the expected life-span of patients with Becker MD; his ambulation ability drastically improved post-HTx, and is still freely ambulatory at his current age of 49 years. Furthermore, patient 4 whose Peak $\dot{\mathrm{VO}}_{2}$ value of the last CPET was $18.7 \mathrm{~mL} / \mathrm{kg} / \mathrm{min}$, continued his own physical exercise training, and ultimately climbed Mount Fuji (3,776m high) 3.8 years after HTx.

The exact etiology of ambulatory recovery in patients with MD after HTx is unknown, but may partially result from recovering disuse muscular atrophy caused by prolonged deconditioning from advanced heart failure during the wait for HTx. Therefore, each patient's ambulatory ability before they developed heart failure, and the levels of activities of daily living while waiting for HTx with LVAD support are both important information for predicting ambulatory recovery after HTx. However, rehabilitation effects on skeletal muscle recovery in patients with MD remain controversial, and aggressive rehabilitation is usually not recommended for patients with MD whose muscles are vulnerable to excessive physical stress. Therefore, we introduced each patient's rehabilitation under close observation of the serum creatine kinase values, a representative marker of muscle breakdown. With respect to medical interventions after HTx, corticosteroids, essential key drugs for immunosuppression after HTx, may have improved the muscular strength of our patients, because glucocorticoid therapy is recognized as a standard treatment for improving muscle strength in Duchenne MD. ${ }^{5}$ Other drugs/treatments after HTx may affect the skeletal muscle function; however, further study is needed to confirm this hypothesis.

In conclusion, HTx can improve the ambulatory capacity of patients with MD. The current case series may broaden the practical impact of HTx therapy in patients with MD based on prognosis and quality of life with respect to the recovery of skeletal muscle and ambulatory capacity.

\section{Acknowledgments}

We thank Yasumasa Ikariyama, Yukihiro Shimada, Eri Miyoshi, Nobuaki Konishi, and Yumiko Hori for their roles in providing patient care.

\section{Conflict of Interest}

The authors have no disclosures or conflicts of interest.

\section{References}

1. Romfh A, McNally EM. Cardiac assessment in Duchenne and Becker muscular dystrophies. Curr Heart Fail Rep 2010; 7: $212-218$.

2. Saito M, Kawai H, Akaike M, Adachi K, Nishida Y, Saito S. Cardiac dysfunction with Becker muscular dystrophy. Am Heart $J$ 1996; 132: 642-647.

3. Seguchi O, Kuroda K, Fujita T, Fukushima N, Nakatani T. Advanced heart failure secondary to muscular dystrophy: Clinical outcomes after left ventricular assist device implantation. $J$ Heart Lung Transplant 2016; 35: 831-834.

4. Wu RS, Gupta S, Brown RN, Yancy CW, Wald JW, Kaiser P, et al. Clinical outcomes after cardiac transplantation in muscular dystrophy patients. J Heart Lung Transplant 2010; 29: 432-438.

5. McDonald CM, Henricson EK, Abresch RT, Duong T, Joyce $\mathrm{NC}, \mathrm{Hu} \mathrm{F}$, et al. Long-term effects of glucocorticoids on function, quality of life, and survival in patients with Duchenne muscular dystrophy: A prospective cohort study. Lancet 2018; 391: $451-$ 461.

\section{Supplementary Files}

Please find supplementary file(s); http://dx.doi.org/10.1253/circj.CJ-18-1060 